\title{
Medical negligence laws and virtual reality in healthcare
}

Ying Yi Lim, Philip Poronnik, Tim Usherwood, Belinda Reeve

\section{Background \\ As technological innovation increases the availability of novel therapeutic options in general practice, healthcare professionals will need to equip themselves with a sound understanding of their professional legal duties in light of emerging medical technologies, including virtual reality (VR).}

\section{Objective}

Using a case study of VR to augment analgesia in burn treatment, this article examines how medical negligence laws apply to the use of new technology in healthcare settings.

\section{Discussion}

While there is currently no positive duty on healthcare professionals to use VR when treating patients, healthcare professionals may be held liable for harm arising from negligent advice or treatment using VR technology. The case study illustrates the flexible nature of negligence principles in adapting to harms arising from new risks such as simulation sickness. Specific warnings and standards of best practice will need to be developed if VR becomes a feature of general practice.
RECENT TECHNOLOGICAL INNOVATIONS offer new therapeutic options in general practice. However, some of these innovations may be associated with risks of harm to the patient if not correctly managed.

One of the most exciting examples of emerging medical technology in healthcare is that of virtual reality (VR). ${ }^{1}$ In the past, VR was very expensive and restricted to aviation and military applications; however, the latest developments in hardware mean that sophisticated VR solutions are now available for less than $\$ 700$ per headset. ${ }^{2}$

Since the technology became more accessible in the mid 2000s, many studies have shown the potential utility of VR in a wide variety of medical fields including pain management, ${ }^{3,4}$ rehabilitation, phobia treatment and palliative care. ${ }^{5}$ The classic example was the demonstration of VR in 2000 by Hoffman and colleagues, using VR as a pain management strategy for the treatment of patients with burns. ${ }^{6-11}$ Patients using VR in combination with analgesia reported significantly reduced pain and anxiety when compared with those using analgesia alone. ${ }^{8-16}$

However, VR treatment can pose risks of harm to particular individuals. For example, 'simulation sickness' resulting in nausea and vertigo may be experienced by some patients during the use of VR. ${ }^{17}$ A recent survey of social media and attitudes to VR highlighted simulation sickness along with vision complications, mobility and disorientation issues, bacterial infections due to the sharing of VR equipment between multiple users as well as unexpected negative effects such as the induction of a psychiatric episode in a patient with psychosis. ${ }^{18}$

In the healthcare arena in Australia, VR is used already in clinical trials and may well be commonplace in general practice in the near future. ${ }^{7,19,20}$ Rather than develop new legislation, existing statutes and bodies of case law may be sufficiently flexible to accommodate the new technologies along with the appropriate safeguards, operating procedures and consent forms. It is therefore important that general practitioners (GPs) refresh their understanding of their professional legal duties in the context of these new technologies and play a part in ensuring that the appropriate clinical standards and legal guidelines are set for the management of the technology.

This article explores how existing medical negligence laws can be applied to the novel risks of new technology through the use of a fictional case study of VR use in healthcare. The case is based on the classic study developed by Hoffman and colleagues on the use of VR for pain management among patients with burns. ${ }^{15}$

\section{CASE}

Callum, aged 21 years, is hospitalised in NSW under the care of Dr Smith for 
second-degree burns to his leg. Dr Smith decides to use VR alongside analgesics as a pain management strategy. She says to Callum, 'We've been trialling virtual reality technology for pain management in patients with burns, and it has been very successful. Would you like to give it a try?' Callum agrees, but he mentions to Dr Smith that he has a history of being susceptible to motion sickness and is concerned about his possible response. Dr Smith assures Callum that he will be fine. Dr Smith sets up a VR game to assist with pain management during the burn wound re-dressing. Despite research trials usually recommending VR use for a maximum duration of five minutes to reduce the risk of nausea, Dr Smith leaves the equipment running for much longer. Prolonged exposure to the immersive game makes Callum nauseated, and he rolls over to vomit during his wound dressing. He falls from the treatment couch as he leans over and fractures his wrist from the impact.

\section{The law: Elements of negligence}

While each state and territory in Australia has its own legislation and body of case law, ${ }^{21,22-26}$ the principles of medical negligence are broadly similar in each jurisdiction. For a patient (eg Callum, the plaintiff) to bring a case of negligence against a doctor (eg Dr Smith, the defendant), the patient needs to establish three main elements (Figure 1):

1. The doctor owed the patient a duty of care.

2. The doctor breached that duty.

3. The doctor's breach caused the harm to the patient.

These three elements to establish negligence accord with principles developed by the courts as well as with relevant state legislation. ${ }^{21-26}$ In the case scenario, the relevant legislation would be the Civil Liability Act 2002 (NSW) ('CLA'). However, our discussion is broadly relevant to medical negligence law across Australia.

This article will focus on elements 1 and 2, exploring how the well-established duty of care owed by healthcare professionals to their patients to 'exercise reasonable care and skill in the provision of professional advice and treatment' ${ }^{\prime 27}$ can be found, and breached, in a VR scenario. Element 3, which is not discussed here, would still need to be established before successfully bringing a negligence action.

While there are other types of actions that will likely be pleaded by a patient in this case (eg failure to advise of alternative forms of treatment), this article will focus on two potential actions: 1 ) the failure to warn Callum of the risks associated with VR use, which is a subset of 2) the failure to exercise reasonable care and skill in his treatment with VR.

Currently, it cannot be said that the use of VR in pain management is so widespread that there is a positive duty on healthcare professionals to offer VR. A healthcare professional would not be held liable for not offering VR. Civil liability would only arise if a healthcare professional chose to use VR and was negligent in doing so.

\section{Potential actions}

\section{Potential action 1: Dr Smith's failure to warn}

The first potential action in negligence may be Dr Smith's failure to warn of the risks of nausea and vertigo, leading to Callum's nausea and wrist injury (Figure 2).

In Rogers $v$ Whitaker ('Rogers'), ${ }^{27}$ the High Court determined that a healthcare professional's duty of care includes an obligation to warn patients of 'material' risks inherent in the proposed treatment. The court in Rogers defined a risk as 'material' when 'a reasonable person in the patient's position, if warned of the risk, would be likely to attach significance to it ["the objective question"]; or if the medical practitioner is or should reasonably be aware that the particular patient would be likely to attach significance to it ["the subjective question"]'. ${ }^{27}$ The materiality of a risk depends on factors such as the nature of the matter to be disclosed, the nature of the treatment and the health of the patient. ${ }^{28}$

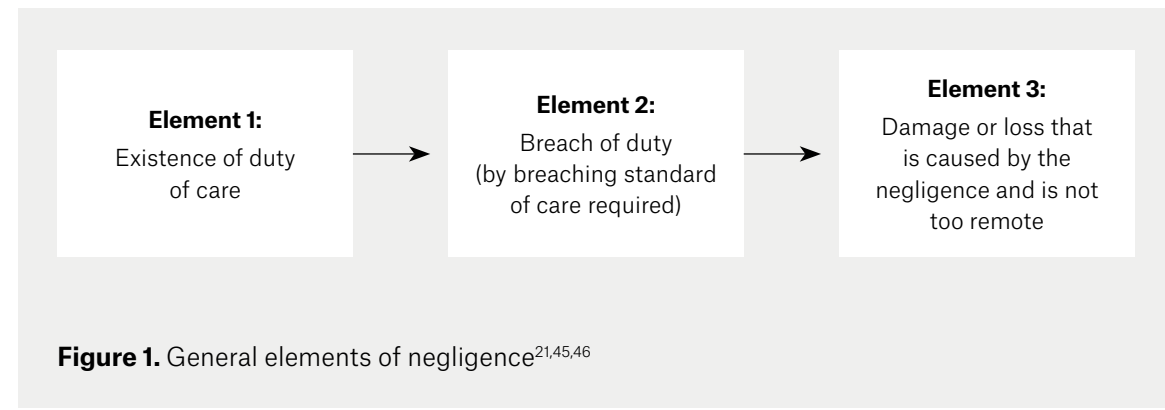


The fact that the probable risk of developing nausea is low $(8 \%)^{12}$ does not determine its materiality. The probability of the patient developing sympathetic ophthalmia in Rogers was one in 14,000, but the risk was still considered material for the patient who was already blind in her other eye. ${ }^{27}$ Similarly, the risk of developing nausea lasting up to four hours and aquiring additional injuries from falling as a result of vertigo is likely to be considered material by a reasonable person in Callum's situation, considering his special susceptibility to motion sickness. ${ }^{21,29,30}$ Even without any special susceptibility, a reasonable patient with burns would want to know about risks well associated with the use of $\mathrm{VR},{ }^{17}$ given the pain the patient would already be experiencing from his burn wounds.

On the alternative subjective limb of the Rogers test, Dr Smith should reasonably have been aware that Callum would likely attach significance to the risk of developing nausea, as Callum had told Dr Smith about his susceptibility to simulation sickness and expressed concern about his response to VR treatment. ${ }^{28}$

It is worth noting that section (s) $5 \mathrm{O}$ of the $C L A$, which prescribes the standard of care for professionals, is precluded by s $5 \mathrm{P}$ of the CLA from applying to liability arising in connection with the duty to warn of risks. As no higher court authority in NSW has clearly established that $\mathrm{s} 5 \mathrm{~B}$ of the $C L A$ applies in relation to failure to warn cases, ${ }^{31-34}$ this article will not explore the application of $\mathrm{s} 5 \mathrm{~B}$ in relation to this action.

\section{Potential action 2: Dr Smith's negligent treatment}

The second potential action in negligence may be Dr Smith's failure to take reasonable care in the provision of VR treatment by administering such treatment for an excessive duration. State civil liability laws generally contain separate provisions on the standard of care expected of professionals; in NSW, this is s $5 \mathrm{O}$ of the $C L A$.

\section{Analysis of section 50}

Under s 5O, liability does not arise for the provision of medical treatment if it is established that a healthcare professional acted in a manner 'widely accepted' in Australia by rational peer professional opinion as competent professional practice. ${ }^{21}$ The healthcare professional bears the onus of proving this and, if successful, the standard of care on which the professional will be assessed will be the one established by this widely accepted professional practice (unless considered by the court to be irrational $[\mathrm{s} 5 \mathrm{O}(2)]) .^{35}$

However, if a 'widely accepted practice' cannot be shown, s 50 will not be engaged, and the court will return to an analysis of the non-professional statutory 'breach of care' provisions in $\mathrm{s} 5 \mathrm{~B}$ of the CLA (Figure 3). ${ }^{35}$

It is unlikely that VR use would constitute a 'widely accepted practice' for wound care in Australia. Despite the wide range of literature on VR treatment, VR use is still confined mostly to clinical research trials rather than clinical applications within 'practice'. ${ }^{15,19,20}$ This amounts to an 'emerging practice' at best. The scope of operation of s 50 has apparently been narrowed in recent NSW cases and can only be established in circumstances where the professional can show that a discrete, established 'practice' has been followed. ${ }^{34}$ Accordingly, s $5 \mathrm{O}$ cannot be relied on in unusual factual situations or, potentially, situations involving new medical techniques or procedures such as the use of VR.

Overall, s $5 \mathrm{O}$ would not be engaged in this case. However, if VR continues to grow in its clinical applications across Australia, this requirement of 'widely accepted practice' could be met in the future.

\section{Analysis of section $5 B$}

Assuming that s $5 \mathrm{O}$ does not apply, the analysis proceeds to consider $\mathrm{s} 5 \mathrm{~B}$ of the $C L A$. Section $5 \mathrm{~B}(1)$ states that a person is not negligent in failing to take precautions against a risk of harm unless the risk was (a) 'foreseeable' and (b) 'not insignificant', and (c) 'a reasonable person in the person's position would have taken those precautions'. 'Precautions' here involve taking adequate steps to ensure that the VR program was run for an appropriate and safe duration of time to minimise the risk of nausea and falling.

The risks of nausea and falling arising from prolonged VR use are foreseeable by a reasonable doctor in Dr Smith's position. In addition to Callum mentioning his particular susceptibility to motion sickness, such risks have been identified by technology manufacturers ${ }^{17}$ and medical researchers. ${ }^{6,11}$ Dr Smith knew, or ought to have known, of the risk of simulation sickness arising from its use. ${ }^{36}$

The phrase 'not insignificant' in $s 5 B(1)(b)$ refers to the probability of the risk occurring. The low number of reported injuries arising from VR simulation sickness does not mean the risk is insignificant. ${ }^{37}$ Rather, documented best practice for VR equipment warning of nausea and falling as a result of vertigo

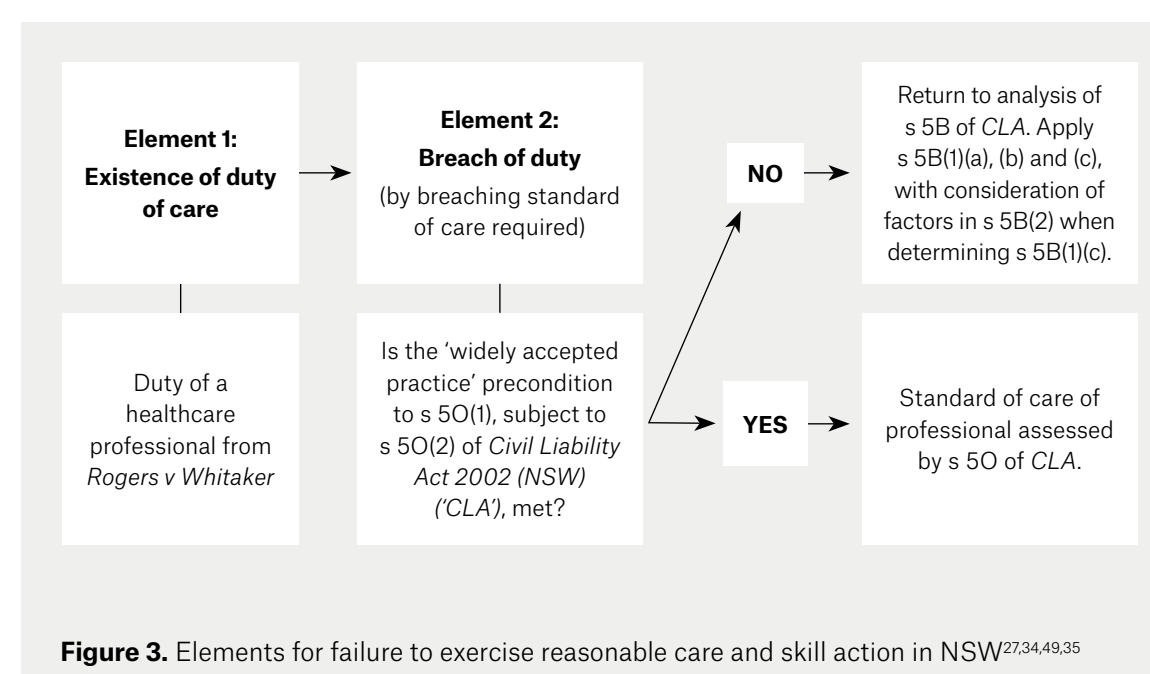

Figure 3. Elements for failure to exercise reasonable care and skill action in NSW27,34,49,35 
and reduced spatial awareness recognises that both risks are 'not insignificant' and should be addressed. ${ }^{17}$

In elaborating on $\mathrm{s} \mathrm{B}(1)(\mathrm{c})$ of the test, $\mathrm{s} 5 \mathrm{~B}(2)$ lists factors to be considered in determining how a reasonable person would respond to 'foreseeable' and 'not insignificant' risks. ${ }^{17}$ Such factors include: (a) 'the probability that the harm would occur if care were not taken', (b) 'the likely seriousness of the harm', (c) 'the burden of taking precautions to avoid the risk of harm', and (d) 'the social utility of the activity that creates the risk of harm'.

A reasonable healthcare professional would likely have taken precautions to limit the duration of VR as it is highly probable that the harm of nausea and falling would occur if such a precaution was not taken. Even for patients of normal susceptibility, studies have shown that prolonging the duration of VR treatment for up to as little as 20 minutes exacerbates the risk of simulation sickness and, consequently, falling. ${ }^{17,38-40}$

The burden of taking precautions to run a shorter VR treatment to avoid the risk of harm is extremely minimal. A reasonable healthcare professional would respond to Callum's susceptibility to motion sickness by choosing an appropriate treatment and safety procedure (or considering not using VR at all). ${ }^{41}$

The social utility of using VR for prolonged durations has yet to be proven in medical studies. ${ }^{40}$ Unlike activities of high social utility such as the driving of ambulances at high speed, the risks arising from prolonged VR use are not outweighed by its social utility as it is neither an essential nor life-saving treatment. ${ }^{42,43}$

Inexperience in handling VR equipment is irrelevant in determining the standard of care owed by a medical professional using such equipment. ${ }^{44}$ However, a practitioner who is known for having special skills in VR may be required to meet a higher standard than an ordinary practitioner. ${ }^{27}$ Therefore, Dr Smith may be held to a higher standard of care in her use of VR if she is considered to be a 'VR specialist'.

Overall, Dr Smith likely breached her duty of care by failing to take reasonable precautions against the risk of Callum developing nausea and vertigo.

\section{Conclusion and recommendations}

VR holds great potential for healthcare and is likely to find application in general practice. ${ }^{6,7,15}$ While it is difficult to anticipate the precise details of how negligence actions may arise in the clinical uses of VR, this case study illustrates the flexible nature of existing negligence law principles in adapting to new social and technological circumstances as they arise.

In this rapidly changing world, it is important that GPs not only maintain awareness of their existing medical professional legal duties but also appreciate how they can be applied to potential medico-legal risks of new technologies such as VR. Specific warnings and standards of best practice will need to be developed to address any gaps in standard of care for treatment with new technologies, in line with scientific evidence regarding their risks and with existing bodies of legal principles. This will be essential for the appropriate management of risks to ensure the best outcomes for both patients and the medical professionals who are responsible for their care.

\section{Authors}

Ying Yi Lim BSc. limyingyi97@gmail.com Philip Poronnik BSc, PhD, Professor of Biomedical Sciences, Discipline of Physiology, School of Medical Sciences Faculty of Medicine and Health, The University of Sydney, NSW

Tim Usherwood BSc, MB, BS, MD (Res), FRCP, FRACGP, FAICD, Professor, General Practice and Head, Westmead Clinical School, Faculty of Medicine and Health, The University of Sydney, NSW

Belinda Reeve BA (Hons), LLB, PhD, Senior Lecturer, The University of Sydney Law School, NSW

Competing interests: None.

Funding: None.

Provenance and peer review: Not commissioned, externally peer reviewed.

\section{References}

1. Facebook Technologies, LLC. Oculus from Facebook. Irvine, CA: Facebook Technologies, LLC 2019. Available at www.oculus.com [Accessed 16 March 2020]

2. Li L, Yu FX, Shi DZ, et al. Application of virtual reality technology in clinical medicine. Am J Transl Res 2017;9(9):3867-80.

3. Li A, Montaño Z, Chen VJ, Gold JI. Virtual reality and pain management: Current trends and future directions. Pain Manag 2011;1(2):147-57. doi: 10.2217/pmt.10.15.

4. Malloy KM, Milling LS. The effectiveness of virtual reality distraction for pain reduction: A systematic review. Clin Psychol Rev 2010;30(8):1011-18. doi: 10.1016/j.cpr.2010.07.001.
5. Austin P, Lovell M, Sidall P. The efficacy of virtual reality for persistent cancer pain: A call for research. J Pain Symptom Manage 2019;58(4):e11-e4. doi: 10.1016/j. jpainsymman.2019.07.009.

6. Li A, Montaño Z, Chen VJ, Gold JI. Virtual reality and pain management: Current trends and future directions. Pain Manag 2011;1(2):147-57. doi: $10.2217 / p m t .10 .15$.

7. Ahamdpour N, Randall H, Choksi H, Gao A, Vaughan C, Poronnik P. Virtual reality interventions for acute and chronic pain mangement. Int J Biochem Cell Biol 2019;114:105568. doi: 10.1016/j. biocel.2019.105568.

8. Mott J, Bucolo S, Cuttle L, et al. The efficacy of an augmented virtual reality system to alleviate pain in children undergoing burns dressing changes: A randomised controlled trial. Burns 2008;34(6):803-08. doi: 10.1016/j. burns.2007.10.010.

9. Hoffman HG, Patterson DR, Carrougher GJ, Sharar SR. Effectiveness of virtual reality-based pain control with multiple treatments. Clin J Pain 2001;17(3):229-35. doi: 10.1097/00002508200109000-00007.

10. Hoffman HG, Patterson DR, Magula J, et al. Water-friendly virtual reality pain control during wound care. J Clin Psychol 2004;60(2):189-95. doi: 10.1002/jclp.10244.

11. Indovina P, Barone D, Gallo L, Chirico A, De Pietro G, Giordano A. Virtual reality as a distraction intervention to relieve pain and distress during medical procedures: A comprehensive literature review. Clin J Pain 2018;34(9):858-77. doi: 10.1097/AJP.0000000000000599.

12. Morris LD, Louw QA, Grimmer-Somers K. The effectiveness of virtual reality on reducing pain and anxiety in burn injury patients: A systematic review. Clin J Pain 2009;25(9):815-26. doi: 10.1097/ AJP.0b013e3181aaa909.

13. Das DA, Grimmer KA, Sparnon AL, McRae SE, Thomas $\mathrm{BH}$. The efficacy of playing a virtual reality game in modulating pain for children with acute burn injuries: A randomized controlled trial [ISRCTN87413556]. BMC Pediatr 2005;5(1):1. doi: 10.1186/1471-2431-5-1.

14. Stewart D, Mete M, Groninger H. Virtual Reality for pain management in patients with heart failure: Study rationale and design. Contemp Clin Trials Commun 2019;16:100470. doi: 10.1016/j. conctc.2019.100470.

15. Hoffman HG, Doctor JN, Patterson DR, Carrougher GJ, Furness TA 3rd. Virtual reality as an adjunctive pain control during burn wound care in adolescent patients. Pain 2000;85(1-2):305-09. doi: 10.1016/s0304-3959(99)00275-4.

16. Rutter CE, Dahlquist LM, Weiss KE. Sustained efficacy of virtual reality distraction. J Pain 2009;10(4):391-97. doi: 10.1016/j.jpain.2008.09.016.

17. Facebook Technologies, LLC. Health and safety warnings. Irvine, CA: Facebook Technologies, LLC, 2019. Available at https://developer.oculus.com/ design/latest/concepts/book-bp [Accessed 15 March 2020].

18. Keller MS, Park HJ, Cunningham ME Fouladian JE, Chen M, Spiegel BMR. Public perceptions regarding use of virtual reality in health care: A social media content analysis using Facebook. J Med Internet Res 2017;19(12):e419. doi: 10.2196/jmir.7467.

19. Monash University. Monash research team trialling virtual reality to help children during medical procedures. Clayton, Vic: Monash University, 2018. Available at www.monash.edu/news/articles/ monash-research-team-trialling-virtual-realityto-help-children-during-medical-procedures [Accessed 16 March 2020]. 
20. St John of God Health Care. World-first virtual reality technology enhancing patient care St John of God Subiaco Hospital. West Perth, WA: St John of God Health Care, 2018. Available at www.sjog.org.au/ news-and-media/news/2018/05/01/00/19/ world-first-virtual-reality-technology-enhancingpatient-care-st-john-of-god-subiaco-hospital [Accessed 16 March 2020].

21. NSW Legislation. Civil Liability Act 2002. Sydney, NSW: NSW Government, 2020.

22. Queensland Legislation. Civil Liability Act 2003. City East, Qld: Queensland Government, 2020.

23. South Australian Legislation. Civil Liability Act 1936. Adelaide, SA: Office of Parliamentary Counsel, 2020.

24. Western Australian Legislation. Civil Liability Act 2002. West Perth, WA: Office of Parliamentary Counsel, 2020

25. Victorian Legislation. Wrongs Act 1958. Melbourne: Office of the Chief Parliamentary Counsel, 2020.

26. Tasmanian Legislation. Civil Liability Act 2002. Hobart, Tas: Office of Parliamentary Counsel, 2020.

27. Rogers v Whitaker (1992) 175 CLR 479.

28. F v R (1983) 33 SASR 189.

29. Rosenburg v Percival (2001) 205 CLR 434.

30. Addison T. Negligent failure to inform: Developments in the law since Rogers v Whitaker. Torts Law Journal 2003;11:165-67.

31. Jambrovic v Day (2017) NSWSC 1468.

32. Biggs v Georg (2016) NSWCA 113.

33. Morocz v Marshman (2016) NSWCA 202

34. Sparks v Hobson; Gray v Hobson (2018) NSWCA 29.

35. South Western Sydney Local Health District v Gould (2018) NSWCA 69.

36. Shoalhaven City Council v Pender (2013) NSWCA 210.
37. Rail Corporation New South Wales v Donald (2018) NSWCA 82.

38. Sydney North Health Network. Virtual \& augmented reality in healthcare. Chatswood, NSW: Available at https://sydneynorthhealthnetwork. org.au/resources/virtual-reality-in-healthcare [Accessed 16 March 2020].

39. Dużmańska N, Strojny P, Strojny A. Can simulator sickness be avoided? A review on temporal aspects of simulator sickness. Front Psychol 2018;9:2132. doi: 10.3389/fpsyg.2018.02132.

40. Kennedy RS, Stanney KM, Dunlap WP. Duration and exposure to virtual environments: Sickness curves during and across sessions. Presence (Camb) 2000;9(5):463-72.

41. McSherry T, Atterbury M, Gartner S, Helmold S, Searles DM, Schulman C. Randomized, crossover study of immersive virtual reality to decrease opioid use during painful wound care procedures in adults. J Burn Care Res 2018;39(2):278-85. doi: 10.1097/BCR.0000000000000589.

42. Villa D. Annotated Civil Liability Act 2002. Pyrmont, NSW: Thomson Reuters, 2013.

43. Hoffman v Boland (2013) NSWCA 158.

44. Imbree v McNeilly (2008) HCA 40.

45. McDonald B, Anderson R, Rolph D. Cases on torts. 6th edn. Alexandria, NSW: Federation Press, 2017.

46. Balkin RP, Davis JLR. Law of torts 5 th edn. Chatswood, NSW: LexisNexis Australia, 2013.

47. Civil Liability Act 2002 (NSW) ('CLA') s 5B, 50 and $5 P$.

48. Judicial Commission of New South Wales. Annotated civil liability act 2002 (NSW). Sydney, NSW: Judicial Commission of New South Wales. Available at https://nswca.judcom.nsw.gov. au/annotated-civil-liability-act/\#section_50 [Accessed 4 May 2020].

49. Civil Liability Act 2002 (NSW) ('CLA') s 5B, 50. correspondence ajgp@racgp.org.au 